\section{Lead hazard in British stained glass workers}

Few studies have been undertaken into lead exposure among stained glass workers. In a recent survey of a studio in the United States Landrigan and his colleagues concluded that the blood lead concentrations were within acceptable limits for occupational exposure. ${ }^{1}$ We have surveyed four stained glass workshops, the largest in Britain, and found that the potential for lead exposure is greater than previously recognised. All the workshops manufactured stained glass and restored windows in churches and other historical buildings; two were attached to cathedrals.

\section{Materials, methods, and results}

A questionnaire was administered to each worker to ascertain job details (including use of protective clothing and masks), personal habits (smoking and nail biting), and symptoms of lead poisoning. Venous blood samples were analysed for lead at the Health and Safety Executive's occupational medicine and hygiene laboratories, which participate in a national quality control scheme. At the largest workshop five background and five personal air samples were obtained during one day while glazing work was performed, and personal samplers were worn by two men on a day when they removed a stained glass window from a historic building.

Altogether 47 exposed workers ( 39 men and eight women) took part and there was only one refusal. The table shows the distribution of blood lead concentrations; the mean was $1.4 \mu \mathrm{mol} / 1(30 \mu \mathrm{g} / 100 \mathrm{ml})($ range $0.5-3.4 \mu \mathrm{mol} / 1$; $10-70 \mu \mathrm{g} / 100 \mathrm{ml})$. Nine workers had concentrations of $1.9 \mu \mathrm{mol} / 1(40 \mu \mathrm{g} / 100$ $\mathrm{ml}$ ) or over, including one woman of reproductive age who had to be temporarily suspended from work with lead in accordance with the British approved code of practice ${ }^{2}$; she worked entirely inside the workshop as a glazier. There were no symptoms of lead toxicity. No relation was found between the mean blood lead values and the type or duration of work performed. Smokers had a higher concentration than non-smokers, but the difference was not statistically significant.

The mean concentration of lead in the personal air samples of five glaziers inside the workshop was $0.03 \mathrm{mg} / \mathrm{m}^{3}$ (range $0.01-0.05 \mathrm{mg} / \mathrm{m}^{3}$ ), and the general atmosphere samples were all $0.01 \mathrm{mg} / \mathrm{m}^{3}$. The range of lead concentrations in air samples for the two men removing windows was $0.01-0.06 \mathrm{mg} / \mathrm{m}^{3}$. All of these were well below the current standard for lead in air of $0.15 \mathrm{mg} / \mathrm{m}^{3} .2$ Bulk samples of cement from the removed windows and workshop floor dust contained $2 \cdot 20 \%$ and $0 \cdot 14 \%$ of lead respectively.

Distribution of blood lead concentrations in 47 stained glass workers

\begin{tabular}{llllllll}
\hline & \multicolumn{8}{c}{ Blood lesd value } \\
\cline { 2 - 8 }$\mu \mathrm{g} / 100 \mathrm{ml}:$ & $10-$ & $20-$ & $30-$ & $40-$ & $50-$ & $60-$ & $\begin{array}{c}70-79 \\
\mu \mathrm{mol} / 1:\end{array}$ \\
\cline { 2 - 9 } & $0 \cdot 5-$ & $1 \cdot 0-$ & $1 \cdot 4-$ & $1 \cdot 9-$ & $2 \cdot 4-$ & $2 \cdot 9-$ & $3 \cdot 4-3 \cdot 8$ \\
\hline No of workers & 11 & 8 & 19 & 7 & 1 & 0 & 1 \\
\hline
\end{tabular}

- Suspension concentration for women $1.9 \mu \mathrm{mol} / \mathrm{l}(40 \mu \mathrm{g} / 100 \mathrm{ml})$, for men $3.9 \mu \mathrm{mol} / \mathrm{l}$ $(80 \mu \mathrm{g} / 100 \mathrm{ml})$.

\section{Comment}

The inhalation of fume or dust containing lead was unlikely by itself to account for the blood lead values exceeding $1.9 \mu \mathrm{mol} / \mathrm{l}$ $(40 \mu \mathrm{g} / 100 \mathrm{ml})$ in nine $(19 \%)$ of the workers studied. We observed that exposure to lead could also occur by ingestion as a result of neglect of basic hygiene precautions-for example, eating and smoking were not always prohibited in areas of lead work, and handwashing facilities were often unavailable on outside sites such as small churches. Few workers perceived that lead was an occupational hazard for them.

Stained glass workers should heed warnings about lead, ${ }^{34}$ and British firms should be reminded about making formal assessments of their work practices as required by the regulations on control of lead at work and described in the approved code of practice. ${ }^{2}$ We recommend a blood lead examination at least yearly. Symptoms of lead poisoning may uccasionally arise at blood lead concentrations below $3.9 \mu \mathrm{mol} / 1$ $(80 \mu \mathrm{g} / 100 \mathrm{ml})$, the current value at which male lead workers in Britain are suspended from work. ${ }^{2}$ In order to protect the fetus women workers of reproductive age are suspended from work when their blood lead concentrations reach $1.9 \mu \mathrm{mol} / 1(40 \mu \mathrm{g} / 100 \mathrm{ml})^{2}$; our findings suggest that this concentration may be readily exceeded. Working with stained glass is becoming an increasingly popular pursuit among both sexes, and it is therefore important that the hazards of excessive lead absorption and its prevention, particularly as they apply to women, should be more widely understood.

We are indebted to the workers and firms who participated in this study We thank Mr D Reeves-Serby and Mr L Smith, Health and Safety Executive, who performed the air sampling; the Health and Safety Executive's occupational medicine and hygiene laboratories for the blood lead analyses and Drs A R L Clark, D A Scarisbrick, and A Wright for field support.

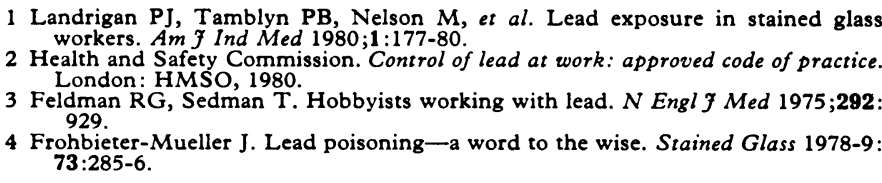

(Accepted 13 May 1985)

Employment Medical Advisory Service (London North Region), Health and Safety Executive, Barking, Essex IG11 8HF

PETER J BAXTER, MD, MRCP, senior employment medical adviser A MARGARET SAMUEL, MRCP, employment medical adviser

Health and Safety Executive, Barking, Essex IG11 8HF

MAUREEN P E HOLKHAM, BA, Her Majesty's inspector of factories

Correspondence and requests for reprints to: Dr P J Baxter.

\section{Anxieties in adolescents about unemployment and war}

Studies in Finland ${ }^{1}$ and America ${ }^{2}$ have noted that the threat of nuclear war is a major source of anxiety in adolescents. We describe a survey carried out in Nottingham of adolescents' hopes and anxieties about the future.

\section{Subjects, methods, and results}

In March 1984, 1797 pupils aged 11-16 from 14 randomly selected secondary schools were asked to complete a questionnaire on health behaviour as part of a cross cultural study coordinated by the World Health Organisation. Data presented here are from two open format questions translated from the Finnish study. ${ }^{1}$ Although respondents could write up to three hopes and anxieties, first named choices are described to allow comparability of results.

The first named anxieties from 1669 respondents aged 11-16 were unemployment from $552(33 \%)$, war $333(20 \%)$, own death $127(8 \%)$, failure in exams $112(7 \%)$, lack of money $91(5 \%)$, and others $454(27 \%)$. First named hopes for the future from 1686 respondents aged $11-16$ were employment from $939(56 \%)$, wealth $123(7 \%)$, happy marriage $99(6 \%)$, good health 91 $(6 \%)$, success in exams $83(5 \%)$, and others $351(20 \%)$.

The most common first named anxiety was unemployment; the proportion rose significantly with increasing age $(134(25 \%)$ of 538 aged $11-12 ; 161$ $(32 \%)$ of 505 aged 13-14; and $257(41 \%)$ of 626 aged 15-16) $(p<0.001)$ The number of respondents citing war as a first named anxiety did not vary with age, and responses of all types of anxieties did not vary by sex.

Among future hopes employment, wealth, and a happy marriage were prominent. More girls $(348(45 \%)$ of 769$)$ than boys $(318(35 \%)$ of 917$)$ hoped for a happy marriage ( $<<0.001)$, and more boys $(411(45 \%))$ than girls $(138(18 \%))$ desired wealth $(p<0.001)$.

From all 1669 responses, including those named first, $853(51 \%), 531(32 \%)$, and $337(20 \%)$ of 11-16 year olds gave unemployment, war, and lack of money as named anxieties, respectively.

Correspondingly, from 1686 respondents employment was cited as a future hope by $1303(77 \%)$ and happy marriages and wealth by $666(40 \%)$ and 549 $(33 \%)$, respectively.

\section{Comment}

There appear to be cross cultural differences in adolescents' anxieties for the future. In Nottingham unemployment was mentioned as a prime cause of anxiety by $25 \%$ of teenagers aged 11-12 years and $41 \%$ aged $15-16$ years. In comparison, it was a prime cause in $7 \%$ of 
12 year old and $19 \%$ of 18 year old Finns. ${ }^{1}$ These differences may be related to the socioeconomic climate in the two countries when the studies were undertaken. The Finnish study was undertaken in February 1983, when the percentage of unemployment was $6 \%$ (abstracts from the Finnish Embassy's annual statistical year book, 1984 (unpublished)), whereas unemployment in the United Kingdom in March 1984 was $13 \%$ and within the city of Nottingham $12 \% .^{3}$

War was the second most cited source of anxiety in adolescents from Nottingham $(133(25 \%)$ of 538 aged $11-12 ; 127(21 \%)$ of 626 aged 15-16; and $333(20 \%)$ of 1669 aged 11-16), though these proportions were considerably smaller than those reported in the Finnish ${ }^{1}$ (79\% aged 12 and $57 \%$ aged 16$)$ and American ${ }^{2}$ (58\% aged 11-19 from a forced choice response) studies. A higher degree of awareness of the threat of war in American compared with English adolescents is not surprising given the state of power of America, and such a difference between England and Finland is not unexpected. Finland has no nuclear weapons, but its proximity to the Soviet Union by a shared border may contribute as much to the degree of public awareness of the nuclear threat as the country's own arms control policy.

This study shows that, in addition to the fear of war, problems of immediate and more personal relevance such as unemployment, poverty, and, especially in girls, unhappy marriages are major concerns of English adolescents. The effects, if any, of these anxieties on the mental and physical health of adolescents are unknown, but the high prevalence of these anxieties suggests that the effects on health of unemployment may extend to those who are at risk of unemployment.

We thank the Health Education Council for supporting this work; the Nottinghamshire education department and the assistant director of education, Mr Peter Housden; and the schools and pupils who participated in this study.

1 Solantaus $T$, Rimpela $M$, Taipale $V$. The threat of war in the minds of 12-18 year olds in Finland. Lancet 1984;i:784-5.

2 Goldenring JM, Doctor RM. Adolescent fears of war. Lancet 1984;i:1022-3.

3 Department of Employment. Employment Gazette. London: HMSO, 1984.

(Accepted 25 May 1985)

Department of Community Health, University of Nottingham, Nottingham NG7 2UH

PAM GILLIES, MED, MMEDSCI, lecturer

J MARK ELWOOD, DSC, $\operatorname{FRCP}(\mathrm{C})$, professor and head of department

PADDY HAWTIN, ONC, SRN, research assistant

Department of Education, University of Manchester, Manchester M13 9PL

FRANK LEDWITH, MA, PHD, research fellow

Correspondence to: Miss Gillies.

\section{Rapid estimation of plasma theophylline concentrations}

Methyl xanthines are used in the treatment of both chronic airways obstruction and asthma. As they have a narrow therapeutic index a knowledge of their plasma concentration is helpful in optimising their clinical effect while avoiding side effects. ${ }^{1}$ It is sometimes desirable to give parenteral methyl xanthines in an emergency, but without knowledge of the patient's plasma theophylline concentration this can be hazardous. In outpatients an increase in theophylline dosage may be clinically desirable but has to be delayed until the plasma concentration is known, which is often not until the patient's next visit. Though measurement of plasma theophylline concentrations is now widely available, only rarely can the result be obtained immediately. Recently a technique of solid phase immunochemistry and reflectance photometry has been developed to measure several variables of blood biochemistry, including theophylline concentrations (Seralyser, Ames Division, Miles Laboratories Ltd). ${ }^{2}$ This machine is designed for use in chemical pathology departments but is portable and simple enough to be operated outside the laboratory. We used this machine to make rapid estimations of plasma theophylline concentrations in the chest clinic.

\section{Patients, methods, and results}

We measured plasma theophylline concentrations in 65 consecutive patients attending our outpatient clinics who had been prescribed a methyl xanthine preparation. Samples were analysed by two different operators using a Seralyser and compared with samples taken simultaneously and assayed by a fluorescence polarisation immunoassay (Abbott TDX)

Venous blood $(10 \mathrm{ml})$ was removed from each patient and centrifuged and the plasma separated into three aliquots. One was sent for independent assay, and the two others were diluted for immediate estimation of the theophylline concentration. The reagent strip was placed on the stage of the photometer and $30 \mu \mathrm{l}$ diluted plasma pipetted on to it. The photometer was activated, the stage replaced, and the result displayed 80 seconds later. If the plasma concentration was lower than $3 \mathrm{mg} / \mathrm{l}$ the machine reported it as zero; if it was greater than $30 \mathrm{mg} / \mathrm{l}$ a further dilution had to be performed. The Seralyse was calibrated with two standard concentrations fortnightly and was checked with an intermediate standard $(15 \mathrm{mg} / \mathrm{l})$ before each outpatient session. Fifty of the patients had measurable concentrations (that is, $>3 \mathrm{mg} / \mathrm{l}$ ).

There was a good correlation between the analyses performed by each of the two operators using the Seralyser and the reference assay in the 50 patients with measurable concentrations (figure). The slopes of the regression lines were 1.02 and 0.99 respectively, and these lines were not significantly different from the line of identity. The $95 \%$ confidence limits about the regression lines were 1.9 and $2.0 \mathrm{mg} / 1$ respectively. The coefficient of variation of repeated measurements for the Seralyser at $15 \mathrm{mg} / \mathrm{l}$ was between $4 \%$ and $5 \%$.

Plasma concentrations in the remaining 15 patients were all recognised by the Seralyser as being below $3 \mathrm{mg} / \mathrm{l}$. Thus there were no false positive results.

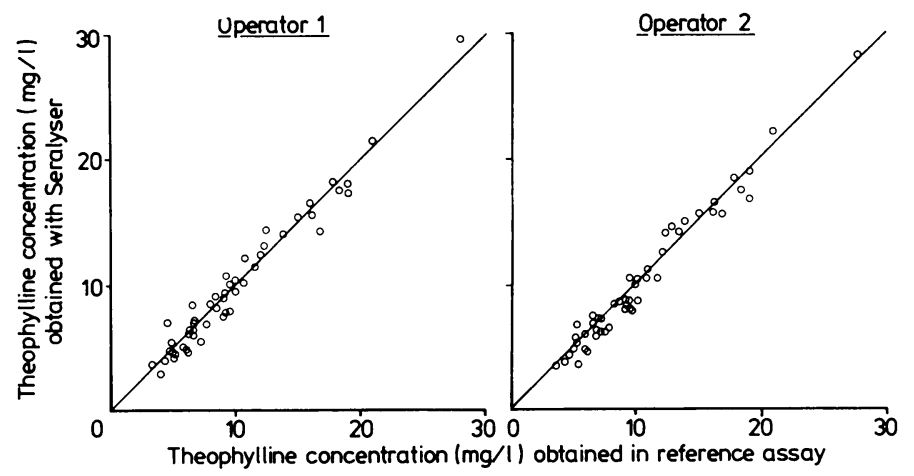

Plasma theophylline concentrations ( $\mathrm{mg} / \mathrm{l}$ ) obtained by two different operators using a Seralyser compared with concentration obtained from reference fluorescence immunoassay $(n=50)$. Line of identity is plotted on each graph.

\section{Comment}

This technique of estimating plasma theophylline concentrations gives good results within five minutes, even when used by relatively inexperienced operators outside a chemical pathology laboratory. It has been suggested that measuring plasma theophylline concentrations adds little to the clinical benefit of administration of methyl xanthines, ${ }^{3}$ and this is probably the case when the result is delayed. We believe that the therapeutic effect of theophylline could be achieved with more speed and certainty by monitoring drug concentrations with a rapid technique. Certainly, immediate estimation of plasma theophylline concentrations would facilitate safer and more confident use of parenteral theophylline in casualty departments. Probably, therefore, the ready availability of plasma theophylline concentrations would lead to more rational and safer use of methyl xanthine preparations.

FMC is supported by Napp Laboratories and JBP by the Medical Research Council. We are grateful to Miles Laboratories for the loan of the Seralyser, for providing the reagents, and for financial support for the reference assay. We also thank David Wood, chemical pathology department, New Ealing Hospital, for performing this assay.

1 Hendeles $L$, Weinberger $M$. Improved efficacy and safety of theophylline in the control of airways hyperreactivity. Pharmacol Ther 1983;18:91-105.

2 Zipp A, Hornby WE. Solid phase chemistry: its principles and applications in clinical analysis. Talanta $1984 ; 31: 863-77$. 1983;38:223.

(Accepted 16 May 1985)

Department of Medicine (Respiratory Division), Royal Postgraduate Medical School, Hammersmith Hospital, London W12 0HS

FRANCIS M CUSS, MA, MRCP, research fellow

JAMES B PALMER, MB, MRCP, research fellow

PETER J BARNES, DM, MRCP, consultant physician

Correspondence to: Dr Cuss. 